\title{
Handling: Effects on eight-arm-maze behavior and hippocampal trace metals
}

\author{
M. D. CHAFETZ and D. L. BERNARD \\ University of Southwestern Louisiana, Lafayette, Louisiana
}

\begin{abstract}
In order to identify the mechanisms by which handling may affect behavior in the adult rat, somatosensory stimulation was manipulated independently of handling time. Multivariate analyses revealed that stroking accounted for more of the variance in behaviors associated with changes in hippocampal function (eight-arm-maze behavior) than did handling time. In a separate test, both holding and stroking increased errors in the eight-arm maze, whereas holding tended to decrease average choice time. Handling was also associated with a reduction in levels of the trace metal copper in the hippocampus. These results are discussed in terms of typical physiological effects of handling as associated with trace metal physiology.
\end{abstract}

The septal-lesion syndrome has been examined as a model of functional recovery after brain damage (Gage, Thompson, \& Valdes, 1978). Shortly after septal damage, a rat becomes hyperreactive to several somatosensory stimuli. This reactivity subsides to preoperation levels within about 2 weeks. If animals with septal lesions are provided with somatosensory stimulation in the form of handling or cage shaking, recovery is enhanced (Seggie, 1968). Because recovery from septal damage is associated in time with changes in neural growth (Chafetz, Evans, \& Gage, 1982) and in chemical features (Gage et al., 1978) of the hippocampus, it is important to determine whether handling affects any of these hippocampal characteristics. Before we can determine how handling may affect recovery, it is important to uncover behavioral and neural mechanisms of the handling effect.

Handling has been considered to be a stressor (Hennessy \& Levine, 1978; Seggie, Uhlir, \& Brown, 1974), a means of arousal (Hennessy \& Levine, 1979), a means of preoperative "gentling" (Albert, Walsh, Ryan, \& Siemens, 1982; Turner, 1970) or "taming" (Coscina, Goodman, Godse, \& Stancer, 1975), or, simply, somatosensory stimulation (Seggie, 1968). With regard to somatosensory stimulation, handling may also be considered as environmental enrichment in that the latter typically includes the augmentation of social and/or sensory stimuli (Doty, 1968; Walsh

The authors wish to express their sincere appreciation to Peter Donovick for reading and commenting on the manuscript. They also wish to thank Ed Bergeron for his immense contribution in data gathering and analyses. These data were presented in preliminary form at the Society for Neuroscience meeting in November 1982 (Chafetz, M. D., Bernard, D. L., Bergeron, E. X., \& Wells, S. Society for Neuroscience, 12th Annual Meeting, 1982, 215.20). M. D. Chafetz's mailing address is: Department of Psychology, University of Southwestern Louisiana, Lafayette, Louisiana 70504. D. L. Bernard is associated with the Department of Physics of the same institution.
\& Cummins, 1976). Each of these behavioral abstractions denote a class of behaviors which uniquely measure the abstraction (Evans, Chafetz, \& Gage, in press), yet investigators have measured the effects of handling on such diverse behaviors as mouse killing (Albert et al., 1982), reactivity (Albert, Chew, Tobani, Walsh, Lee, \& Ryan, 1981; Albert et al., 1982), and learning (Doty, 1968). Each of these abstractions may also implicate a different physiological mechanism of effect. For example, "arousal" and "stress" may invoke an adrenocortical response (Hennessy \& Levine, 1979), while somatosensory stimulation typically implies a neural effect (Dietrich, Durham, Lowry, \& Woolsey, 1982).

Accordingly, animals have been handled in different ways, especially by amount of handling (Seggie, 1968) and by the duration of handling (Coscina et al., 1975). In most studies, these handling codes are confounded, so that it becomes difficult to parcel out putative mechanisms. For example, picking up an animal for a period of time may provide an adrenocortical response (Hennessy \& Levine, 1978; Seggie et al., 1974), whereas stroking an animal may add additional (confounded) sensory stimulation (Lanıour, Willer, \& Guilbaud, 1983).

The purposes of this study, therefore, were: (1) to identify the handling method, or code, that most affected behaviors sensitive to changes in hippocampal function; and (2) to determine whether those behaviors formed a class manipulated uniquely by handling. Multivariate analyses were used to identify the most important handling code and to aggregate individual behaviors empirically associated with unique classes of behavior (Evans et al., in press). Because the hippocampus binds adrenocortical hormones with high sensitivity (McEwen \& Wallach, 1973) and has units that respond to somatosensory stimulation (Vinogradova, 1975), a behavioral test involving hippocampal function was desirable. We used the eight- 
arm maze procedure as a behavioral test sensitive to changes in hippocampal function (Olton, Walker, \& Gage, 1978). Finally, particle-induced X-ray emission (PIXE) analysis was used to measure changes in levels of heavy metals in the hippocampus (Kemp \& Danscher, 1979). Heavy metals were studied because iron, zinc, and copper are associated with hippocampal enzymes that are affected by glucocorticoid activity (Dailey \& Battarbee, 1982), because zinc is a regulator of nerve growth factor subunit binding (Pattison \& Dunn, 1975), and because stressors have been shown to affect serum copper and zinc levels (Armario, Balasch, \& Martinez, 1981). Changes in hippocampal structure and/or function may therefore be associated with heavy metals effects.

\section{METHOD}

\begin{abstract}
Animals
Thirty Sprague-Dawley rats weighing $300-500 \mathrm{~g}$ during testing were housed individually in a temperature-controlled $\left(21^{\circ}\right)$ vivarium. The animals were maintained on a 12-h:12-h reversed lighting cycle with lights off at $0700 \mathrm{~h}$. They had ad-lib access to Lab Chow and water.
\end{abstract}

\section{Experimental Design and Analysis}

Phase 1. The 30 rats were allocated randomly to two replication groups of 15 rats each. Each rat was assigned at random a number of strokes between 0-42 in multiples of 3. Each rat was also assigned at random a total handling (stroking) time of $0-420 \mathrm{sec}$ in units of $30 \mathrm{sec}$. (The 0 time was, in practice, $15 \mathrm{sec}$.) One may conceive of these manipulations as dose-response allocations of handling time and of stroking with 15 different dosage levels of each. Because each animal was assigned a handling time and a number of strokes randomly, these manipulated variables were empirically irsependent $(|\mathrm{r}|<.1)$ and therefore unconfounded.

To hold each animal, the experimenter cradled it against his chest, restraining the animal by its tail to prevent escape. While the rat was being cradled, the experimenter cupped his other hand and stroked the rat from head to tail.

These manipulations were continued daily for 3 weeks, and this protocol defined Phase 1 of the study. Behavior in the Olton eight-arm radial maze was recorded at the end of each week. For this task, food-deprived animals were placed in the center arena of the maze and allowed to choose from eight maze arms, each of which contained a food reward. Optimal choice behavior under these conditions was to choose eight different arms. Under these conditions, a return trip to any arm previously entered was considered to be an error (Olton \& Samuelson, 1976). The behaviors observed for this task included: total time to choose eight arms (TT), average time spent in the center octagon between choices (AT), number of errors (E), turning bias (RT and LT), and number of rearings (R), groomings (GM), sniffings (S), and head raises (UH). It was considered important to study the typical exploratory behaviors in addition to the eight-arm-maze behavior because of the well-known effects of infantile handling on adult exploration (DeNelsky \& Denenberg, 1967) and because adult handling may also affect exploration (Bengelloun, Finklestein, Burright, \& Donovick, 1977).

The subgoals of this first phase were to describe the pattern of behaviors associated with each handling code (amount and time), and to identify the handling code that best accounted for the behaviors sensitive to changes in hippocampal function. Principal components analysis is ideally suited to these tasks. A principal component is a linear combination of the variables accounting for the most shared variance among them. The variables that correlate most highly with (exhibit the highest weights on) the principal component share the most variance and are therefore the ones that exhibit the highest intercorrelations. The first principal component is that linear combination accounting for the most variance in the data set, but it is not necessarily exhaustive of the variance. Succeeding components may be formed from the residuals of the preceding component until $100 \%$ of the variation is accounted for. In this way, each component is orthogonal. If there are substantial intercorrelations, most of the variance will be accounted for by a few components, thereby achieving data reduction (Evans, Neideffer, \& Gage, 1981).

The manipulated variables of time and stroking were included with the observed variables in the principal components analysis. Because the manipulated variables were constructed to be orthogonal, they were expected to correlate with different orthogonal components. The analysis therefore permitted the empirical identification of the most important handling code by showing which handling code correlated with the first (most important) principal component. The other handling code would then account for less variance. Secondly, the specific behaviors most highly correlated with each handling code could then be easily described with reference to the principal components associated with each handling code. The analysis was performed on both replication groups simultaneously (two animals per manipulation level) so that the matrix consisted of 30 cases $\times 9$ variables.

In the analysis described above, each two individuals represented a different experimental condition. The analysis cumulated over the experimental conditions so that the main bases for the intercorrelations among the variables were the effects of each manipulation (Evans et al., in press). Individual differences were therefore confounded with the effects of manipulation, but the treatment effects were expected to be much greater and to dominate the results (Evans et al., in press). It was nevertheless desirable to determine the effects of the different handling codes with a design not confounded by individual differences. A different design and analytic strategy was therefore employed in Phase 2.

Phase 2. In Phase 2, 15 of the previously used rats were allocated randomly to three different groups: 5 animals were stroked 60 times in 1 min (STR), 5 animals were held for 1 min but not stroked (held), and 5 animals were left isolated in their cages (CONT). One animal in this group subsequently died, leaving a total of 14 animals allocated to the three groups. These manipulations were conducted daily for 4 weeks, and then three consecutive daily behavioral observations were recorded. The behavioral observations additionally included open-field activity and rearing (Bengelloun et al., 1977). The animals were permitted 3 min exploration time in the open field. The behaviors that were analyzed therefore included eight-arm-maze total time (TT), errors (E), average choice time (AC), rearing (RE), and open-field rearing (RO) and activity (lines crossed) (LNS).

In this phase, the identification of the most important handling code requires asking which pattern of behavioral changes best permits a distinction to be made between three groups that differ in the type of handling received: no handling (CONT), handling (HELD), and handling plus stroking (STR). The analysis most suited to this question is discriminant function analysis.

A discriminant function is a linear combination of dependent variables that achieves maximal separation between groups (maximal between-groups variance). The first discriminant function accounts for the most between-groups variance possible in the data set, but it too is not necessarily exhaustive of this variance. Residual variance is then examined for succeeding (orthogonal) discriminant functions which may account for a different pattern of group differences. The number of discriminant functions that can be formed in any data set is one less than the number of groups, so there were two functions possible in the present data set. Because these functions are orthogonal, it is possible to show the dimensionality of group differences by showing the pattern of behaviors that differentiate groups on each dimension (Klecka, 1980). This is important in the present case because the different handling codes may each yield a different pattern of behavioral changes that could imply different mechanisms. 
Phase 3-Analysis of heavy metals. The animals were then decapitated for analysis of hippocampal levels of heavy metals. Particle-induced X-ray emission analysis (PIXE) was used (Kemp \& Danscher, 1979). Hippocampi were dissected free and placed in $10 \%$ Formalin for several days. The fixed tissue was then ground with a mortar and pestle and placed between two sheets of mylar (0.1-mil thickness) held in place in a $35-\mathrm{mm}$ slide holder. An $80-\mu$ drop of $.025 \mathrm{M} \mathrm{H}_{2} \mathrm{PtCl}_{6}$ was dried on the outside (beam side) of each slide face to use as an internal X-ray emission standard. A KN 3000 Van de Graaff electrostatic accelerator was used to accelerate $2.5-\mathrm{MeV}$ protons. The proton beam, with a current of about $30 \mathrm{nA}$, was allowed to exit the accelerator vacuum system via a 0.25-mil-thick Kapton foil. Upon leaving the foil, the proton beam enters a specially designed specimen chamber filled with $1 \mathrm{~A}_{\mathrm{s}}$ of helium. The beam travels about $2 \mathrm{~cm}$ in the helium until it strikes the specimen, which is tilted $135 \mathrm{deg}$ with respect to the incident beam direction. $\mathrm{A} \mathrm{Si}(\mathrm{Li})$ solid state $\mathrm{X}$-ray detector was used to record the energy and quantity of $\mathrm{X}$-rays emitted by the specimens. Counts were recorded at the energies characteristic of $\mathrm{Zn}, \mathrm{Fe}$, and $\mathrm{Cu}$ emissions. 'The counts of each element were normalized by a factor obtained from the standard $\mathrm{Pt}$ counts for each run. This was done by finding the percent of the overall mean $\mathrm{Pt}$ reading for each run and using .01 of this value for the divisor. Differences in beam fluctuations were therefore all normalized to the mean Pt count. The counts were also normalized to a standard beam area to account for fluctuations in hippocampal size. The metals data were also subjected to a discriminant function analysis to examine the (metals) variables that best differentiated between the experimental handling groups.

\section{RESULTS}

\section{Phase 1}

The subgoals in Phase 1 were to describe the pattern of behaviors associated with each handling code and to identify the handling code that best accounted for the behaviors sensitive to changes in hippocampal function. Table 1 shows the correlations of each of the behaviors with the independent handling codes. The table shows that the handling manipulations did not begin to take effect until the third week of observation. On this observation, the stroking code exhibited statistically significant correlations with the average time in the center octagon (AT) $[\mathrm{r}(28)=.41$,

Table 1

Correlations of Behaviors with Handling Manipulations

\begin{tabular}{|c|c|c|c|c|c|c|}
\hline & \multicolumn{2}{|c|}{ Week 1} & \multicolumn{2}{|c|}{ Week 2} & \multicolumn{2}{|c|}{ Week 3} \\
\hline & STR & $\mathrm{TM}$ & STR & TM & STR & TM \\
\hline $\mathrm{TT}$ & .24 & .13 & .18 & $-.36 *$ & $.37 *$ & -.12 \\
\hline AT & .07 & -.14 & -.06 & -.31 & $.41^{*}$ & .02 \\
\hline E & -.24 & -.05 & .07 & .05 & $.40 *$ & .24 \\
\hline RT & -.01 & .02 & .08 & .14 & .03 & -.29 \\
\hline LT & -.06 & -.01 & -.08 & .14 & -.08 & .15 \\
\hline S & .21 & -.03 & -.03 & .03 & .12 & .30 \\
\hline $\mathbf{R}$ & .08 & .05 & .11 & -.30 & $.48 * *$ & -.35 \\
\hline G & -.09 & .02 & .14 & -.28 & -.08 & -.08 \\
\hline UH & .12 & .13 & .34 & -.09 & -.03 & .01 \\
\hline
\end{tabular}

Note $-S T R=$ strokes; $T M=$ handling time; $T T=$ total maze time; $A T=$ average time in center octagon; $E=$ errors; $R T=$ right turns; $L T=$ left turns; $S=$ sniffing; $R=$ rearing; $G=$ grooming; UH $=$ upraised head. $\quad{ }^{*} p<.05 . \quad{ }^{* *} p<.01$.
Table 2

Principal Components Analysis Results From Third Handling Week

\begin{tabular}{lccc}
\hline & \multicolumn{3}{c}{ Factor Matrix } \\
\cline { 2 - 4 } & PC1 & PC2 & COM \\
\hline TT & $.82^{*}$ & .05 & .67 \\
AT & .64 & .07 & .42 \\
E & .43 & .19 & .22 \\
RT & -.19 & $-.90^{*}$ & .85 \\
LT & .14 & $.88^{*}$ & .79 \\
S & .15 & .04 & .02 \\
R & $.74 *$ & -.29 & .63 \\
G & .10 & -.11 & .02 \\
UH & .45 & .32 & .30 \\
STR & $.72 *$ & -.25 & .58 \\
TM & -.18 & .53 & .31 \\
TBS & -.68 & .17 & .49 \\
PVR & .26 & .18 & \\
CPV & .26 & .44 & \\
\hline
\end{tabular}

Note $-P C=$ principal component $; C O M=$ communality $; P V R=$ proportion of variance; $C P V=$ cumulative proportion of variance; $T B S=$ time between strokes; other abbreviations given in Table 1. *Variables sharing at least half their variance with the compo. nent.

$\mathrm{p}<.05]$, the total time in the maze $(\mathrm{TT})[\mathrm{r}(28)=.37$, $\mathrm{p}<.05]$, the number of errors $(\mathrm{E})[\mathrm{r}(28)=.40, \mathrm{p}<.05]$, and the number of rearings $(\mathrm{R})[\mathrm{r}(28)=.48, \mathrm{p}<.01]$. Although the time code did not correlate significantly with any one behavior on this observation, there were two correlations that approached statistical significance: rearing $(R)(r=-.35)$ and sniffing $(S)(r=.3)$. Also, on the second observation (Week 2), the time code exhibited a statistically significant correlation with the total time spent in the maze $\operatorname{Ir}(28)=-.36$, $\mathrm{p}<.05]$. Although there was some tendency for the time code to correlate with some of the behaviors on the second week of observation, only one of the correlations was statistically significant. It were therefore desirable to examine the third observation with the principal components analysis.

The principal components analysis showed that the stroking code correlated more highly with the first principal component while the time code was more highly associated with the second principal component (Table 2). The individual behaviors that best defined the first, or stroking, component were TT and $\mathbf{R}$. These variables shared at least half their variance with this first component. Other variables that were moderately highly correlated with this component were AT and time between strokes (TBS). The TBS variable was derived from the stroking and time codes by dividing the amount of time by the number of strokes but is not particularly interesting because of its correlation with the stroking component.

The second component was largely defined by the turning behaviors (RT and LT) which were, of course, highly correlated. 
Table 3

Discriminant Analysis Between Handling Groups

(a) Discriminant Function Analysis Standardized Coefficients

\begin{tabular}{|c|c|c|c|c|c|c|c|c|}
\hline & \multicolumn{2}{|c|}{ Standardized Coefficients } & \multicolumn{6}{|c|}{ (b) Means and Standard Deviation (SD) for Each Behavior } \\
\hline & \multirow[b]{2}{*}{ DF1 } & \multirow[b]{2}{*}{ DF2 } & \multicolumn{2}{|c|}{ STR } & \multicolumn{2}{|c|}{ HELD } & \multicolumn{2}{|c|}{ CONT } \\
\hline & & & Mean & SD & Mean & SD & Mean & SD \\
\hline TM & 20.5 & 8.4 & 106 & 48 & 66 & 16 & 87 & 11 \\
\hline $\mathrm{E}$ & 1.8 & 1.8 & 1.8 & .4 & 1.8 & .4 & .75 & .5 \\
\hline RE & -4.7 & -1.1 & 8.6 & 5.5 & 4.0 & 3.2 & 3.5 & 2.6 \\
\hline RO & 1.4 & .6 & 12 & 1 & 13 & 4 & 13 & 3 \\
\hline $\mathrm{AC}$ & -16.2 & -7.9 & 17 & 7 & 11 & 3 & 12 & 2 \\
\hline LNS & 1.3 & .5 & 75 & 18 & 81 & 21 & 73 & 15 \\
\hline PVR & $.86^{*}$ & .38 & & & & & & \\
\hline
\end{tabular}

Note $-D F=$ discriminant function; $T M=$ time eight-arm maze; $E=$ errors; $R E=$ rearing eight-arm maze; $R O=$ rearing open field AC = average choice; $L N S=$ lines crossed open field; $S T R=$ stroked $H E L D=$ held; $C O N T=$ control; $P V R=$ proportion between groups variance. $\quad{ }^{*} p<.05$.

\section{Phase 2}

In this phase it was desirable to identify the pattern or set of intercorrelations of behavioral variables that best distinguished between the three handling groups: CONT, HELD, and STR. The behavioral observations included open-field behaviors in addition to the eight-arm-maze behaviors. The discriminant analysis shown in Table 3a indicates that the first discriminant function accounted for $86 \%$ of the between-groups variance, while the second (orthogonal) discriminant function accounted for $38 \%$ of the remaining betweengroups variance. Only the first function was statistically significant $\left[\chi^{2}(12)=21.3, \mathrm{p}<.05\right]$. The table shows that TT and AC were most highly weighted on this function, albeit in opposite directions despite their high positive correlation. Table $3 \mathrm{~b}$ provides the means and standard deviations for each behavior.

There were, however, substantial intercorrelations between RE and $\mathrm{E}(\mathrm{r}=-.54)$, LNS and RO $(\mathrm{r}=.55)$, LNS and AC $(r=-.52)$, and AC and TT $(r=.97)$. High individual correlations such as these will sometimes add suppressor effects to the discriminant analysis, thereby clouding the interpretation of the discriminant weights. For example, AC and TT were highly correlated in the positive direction yet weighted in opposite directions on the discriminant function (Klecka, 1980). It was therefore desirajle in this case to perform a discriminant analysis on a reduced set of variables. The variables chosen for this reduced analysis were the eight-arm-maze variables $\mathrm{AC}$ and $\mathrm{E}$.

This discriminant analysis (Table 4) shows that there were two discriminant functions that accounted for substantial between-groups variance. The first accounted for $58 \%$ of the between-groups variance $\left[\chi^{2}(4)=12.7, p<.05\right]$, while the second accounted for $29 \%$ of the remaining between-groups variance $\left[\chi^{2}(1)=3.7, p<.06\right]$. The $E$ variable correlated most highly with the first discriminant function, while the AC variable correlated most highly with the second. Because $\mathrm{E}$ and $\mathrm{AC}$ were not correlated $(\mathrm{r}=-.12)$, it was not surprising to find that they correlated with different (orthogonal) functions. The errors (E) variable, however, was identified as being the most important in separating the three handling groups.

Table 4

Discriminant Analysis of Handling Groups (Reduced Set of Variables) Standardized Coefficients

\begin{tabular}{llc}
\hline & DF1 & DF2 \\
\hline E & .98 & -.19 \\
AC & .16 & .99 \\
PVR & $.58^{*}$ & $.29^{*}$ \\
\hline
\end{tabular}

Note $-D F=$ discriminant function; $E=$ errors; $A C=$ average choice; $P V R=$ proportion between groups variance. $\quad{ }^{*} p<.05$.

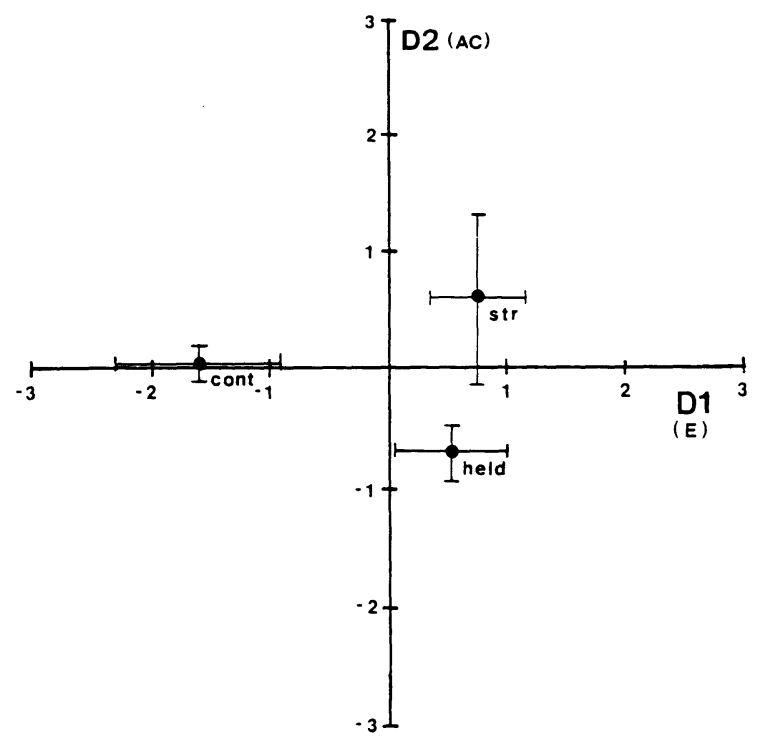

Figure 1. The means (centroids) for each group on each discriminant function are shown with the standard errors. The first discriminant function (D1) is represented on the $x$-axis; the second function (D2) is represented on the y-axis. Both stroking (str) and holding (held) increase errors (E weights highly on D1) relative to the absence of handling (cont). Holding tends to decrease average choice time (D2). 


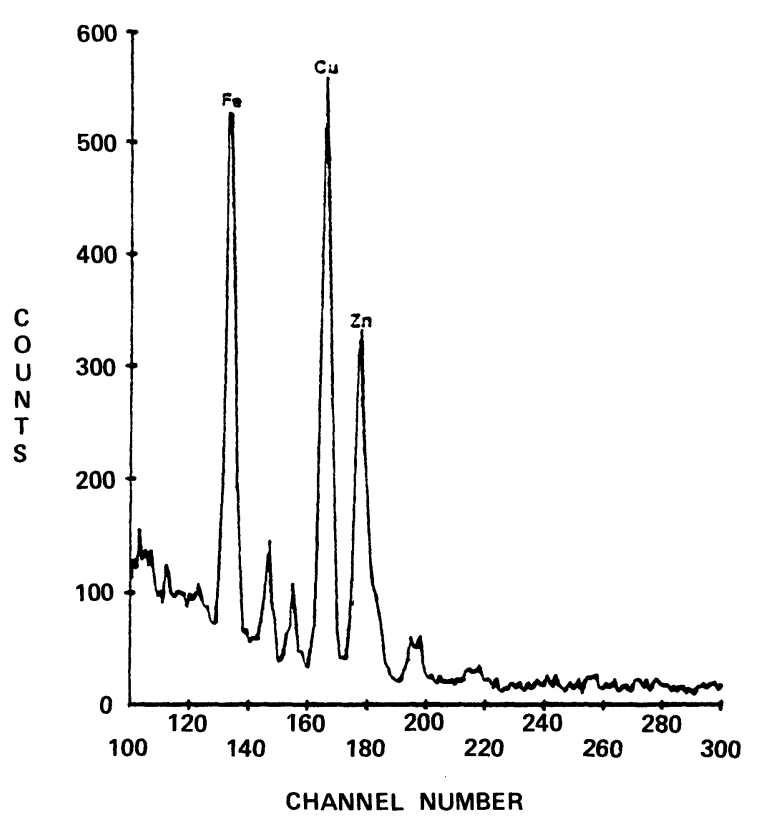

Figure 2. Typical spectrum of counts from particle-induced $x$-ray emission analysis showing peaks corresponding to specific heavy metals in the hippocampus.

Figure 1 is a graphic representation of this discriminant analysis. The figure shows the group centroids, or means, for both discriminant functions plotted simultaneously for each of the handling groups. The first function (represented by errors) is plotted on the $\mathrm{x}$ axis, and the second function (represented by average choice time) is plotted on the $y$ axis. From the graph, it is clear that the control group (CONT) made fewer errors in the eight-arm maze than did the stroking (STR) or holding (HELD) groups. In addition, holding seemed to reduce the average choice time in this maze.

\section{Phase 3}

Figure 2 depicts the spectra of counts from a typical particle-induced X-ray emission (PIXE) analysis showing the peaks corresponding to specific heavy metals in the brain. The channel number (x-axis) is configured to sense different X-ray energy levels. Each metal has a characteristic energy level, and the relative amount of metal present is measured by the counts (y-axis) at the correct energy level. The counts were normalized as described in the methods section and included in the analysis with the previously described behaviors.

There were high intercorrelations between the metals $\mathrm{Zn}, \mathrm{Fe}$, and $\mathrm{Cu}$ (Table 5). The table also shows that the metal $\mathrm{Cu}$ tended to be moderately correlated with the eight-arm-maze behaviors $E$ and RE. Because of the previously mentioned problems in interpreting a discriminant analysis on highly correlated variables, a discriminant analysis was performed on a reduced set of variables using $\mathrm{Cu}$ as representative of the metals.

This discriminant analysis revealed that errors (E) in the eight-arm maze and hippocampal $\mathrm{Cu}$ levels served to differentiate the handling groups on the first (significant) discriminant function $\left[\chi^{2}(6)=15.3\right.$, $\mathrm{p}<.02]$. Average choice time served to differentiate the groups primarily on the second function, but this result was not statistically significant. Table 6 shows that $\mathrm{Cu}$ and $\mathrm{E}$ were weighted in opposite directions on this first function. Given this weighting scheme, Figure 3 shows that holding and stroking tend to increase errors and reduce copper levels, whereas stroking tends to increase average choice time (not significant). A similar analysis was performed using $\mathrm{Zn}$ instead of $\mathrm{Cu}$ as the metal, but there were no statistically reliable results.

\section{DISCUSSION}

The results show that the handling code that most affected behaviors sensitive to changes in hippocampal function was stroking. As animals are increasingly stroked, they make more errors in the radial eight-arm maze, show an increased number of rearings, and spend more time in the maze, especially in the center octagon. This manipulation appears to be more effective than the holding manipulation in altering these behaviors. In

Table 5

Correlation Matrix Showing Behavior and Metals Analysis

\begin{tabular}{|c|c|c|c|c|c|c|c|c|}
\hline & E & $\mathrm{RE}$ & RO & $\mathrm{AC}$ & LNS & $\mathrm{ZN}$ & $\mathrm{FE}$ & $\mathrm{CU}$ \\
\hline E & 1.00 & & & & & & & \\
\hline RE & $-.54 *$ & 1.00 & & & & & & \\
\hline RO & -.38 & .07 & 1.00 & & & & & \\
\hline $\mathrm{AC}$ & -.12 & .70 & -.20 & 1.00 & & & & \\
\hline LNS & -.14 & -.17 & $.55^{*}$ & $-.52^{*}$ & 1.00 & & & \\
\hline $\mathrm{ZN}$ & .28 & -.44 & .05 & -.42 & .31 & 1.00 & & \\
\hline $\mathrm{FE}$ & .17 & -.34 & .14 & -.26 & .42 & $.92^{* *}$ & 1.00 & \\
\hline $\mathrm{CU}$ & .46 & $-.50^{*}$ & -.12 & -.38 & -.14 & $.67 * *$ & .44 & 1.00 \\
\hline
\end{tabular}

Note $-E=$ errors; $R E=$ rearing eight-arm maze; $R O=$ rearing open field; $A C=$ average choices; $L N S=$ lines; $Z N=z i n c ; F E=$ iron; $C U=$ copper. $\quad * p<.10 . \quad * * p<.05$. 
Table 6

Discriminant Function Analysis Showing Handling Effects on Behavior and Metals

\begin{tabular}{lcc}
\hline & DF1 & DF2 \\
\hline E & -.90 & -.57 \\
AC & .42 & -.86 \\
CU & 1.07 & -.31 \\
PVR & $.75^{*}$ & .41 \\
\hline
\end{tabular}

Note $-D F=$ discriminant function; $E=$ errors; $A C=$ average choice; $C U=$ copper $P V R=$ proportion between groups variance. $\quad{ }^{*} p<.02$.

that the stroking amount and the holding time were randomly allotted to the animals, it appears that these effects of stroking can be assessed independently of the holding time. In studies that utilize handling as a manipulation, it may therefore be critical to consider the mode of handling administered.

When these manipulations were allotted to different animals (in separate groups), it appeared that each manipulation had a different kind of effect. Both stroking and holding tended to increase the errors made in the eight-arm maze, whereas holding tended to reduce the average choice time. This analysis indicated that behavior in the eight-arm radial maze may be differentiated into two classes on the basis of the effects of handling. One class may be associated with the errors made by the animals, whereas the other (orthogonal) class may be associated with traversal time. Handling should therefore not be used to denote "stress" or "reward" (Kostarczyk \& Fonberg, 1982)

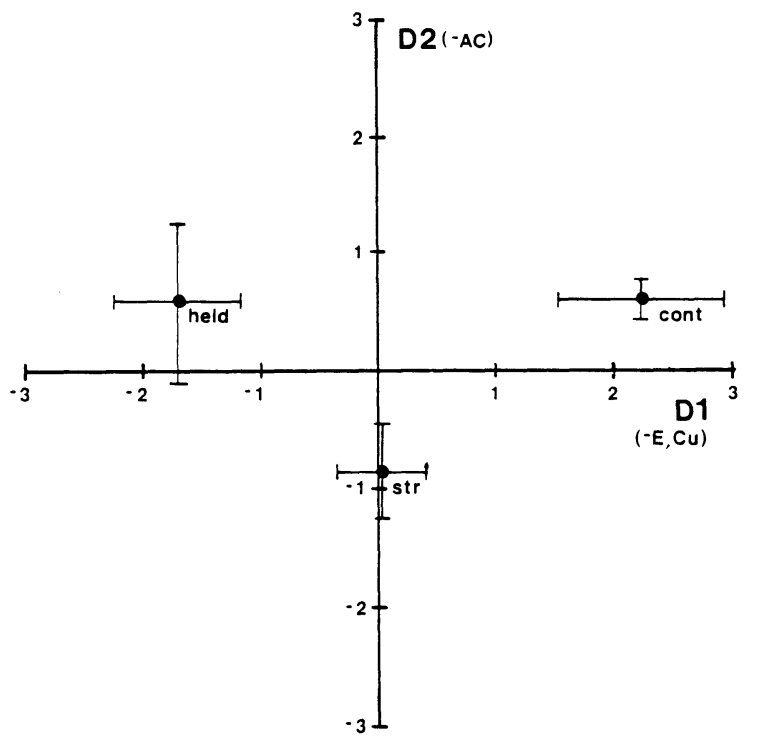

Figure 3. Discriminant analysis including hippocampal copper counts with the behaviors shown in the previous analysis (Figure 1). The directions for the behavioral variable weights are now reversed: D1 now increases with decreasing errors, whereas D2 increases with decreasing choice time. Cu levels increase on D1. As shown here, handling not only increases errors but decreases hippocampal copper levels. or any other psychological construct unless it can be demonstrated that an equivalence class of appropriate behaviors is being manipulated (Evans et al., in press). The requirements for an equivalence class involve an analysis of the intercorrelations among appropriately measured variables. These requirements are discussed extensively in Evans et al. (in press) and are beyond the scope of the present paper. What is interesting to note is that the association of handling with conflicting constructs seems to have resulted from an a priori focus on these constructs. In the present paper, handling is empirically associated with variables that imply different mechanisms.

This dissociation of the behavioral effects of handling may hold some importance for the analysis of the different physiological effects of handling. While both holding and stroking may increase corticosteroid levels (Hemsworth, Barnett, \& Hamen, 1981; Hennessy \& Levine, 1978; Seggie et al., 1974), stroking may be additionally associated with increased somatosensory stimulation (Lamour et al., 1983), and increased levels of steroids (Hemsworth et al., 1981), both of which may be expected to have effects on hippocampal neurons (McEwen \& Wallach, 1973; Vinogradova, 1975). Both added stimulation (Bengelloun et al., 1977; Donovick, Burright, \& Swidler, 1973; Doty, 1968) and corticosteroid levels (Ogren \& Fuxe, 1977) have been shown to have effects on behaviors and/or cortical systems associated with learning or exploration, so that it would be invaluable to take direct measures of the physiological effects of these manipulations. In any case, our dissociation of the two kinds of handling - holding and stroking - could be due to increased steroid levels, to increased somatosensory stimulation, or to an interaction of the two acting on hippocampal systems.

With regard to hippocampal effects, our data show reduced hippocampal copper levels associated with increased errors in the holding and stroking groups, although these latter groups cannot be differentiated on the basis of changes in heavy metal counts. Handling may therefore have effects on trace metals in the hippocampus. Although the mechanism is presently unknown, it is conceivable that handling could exert its effect in several ways. Glucocorticosteroids have been shown to modulate the induction of neurotransmitter synthetic enzymes in the superior cervical ganglion (Otten \& Thoenen, 1976). Dopamine beta-hydroxylase is a cuproenzyme (Prohaska \& Smith, 1982), and dietary copper deficiency will increase the activity of dopamine beta-hydroxylase (Prohaska \& Smith, 1982). Also, Colburn and Maas (1965) showed that magnesium, iron, zinc, and copper form ternary complexes with norepinephrine and ATP and that norepinephrine uptake was inhibited by a chelating agent. Given that corticosterone has an effect on B-adrenergic receptor binding in the hippocampus (Roberts \& Bloom, 1981) and on cuproenzyme 
activity (Prohaska \& Smith, 1982), regulation of trace metals by handling could be brought about by regulation of activity in noradrenergic systems.

These data complement the findings of Armario et al. (1981), who showed that stressors alter serum copper but not serum zinc levels in rats. Their data showed that $60 \mathrm{~min}$ of acute stress plus $30 \mathrm{~min}$ of rest elevated serum copper levels. Although the direction of change in hippocampal copper levels was different (lowered) in the present study, it is conceivable that alterations in the induction of brain cuproenzyme activity could have a regulatory effect on serum trace metals.

One other finding of interest in this study was the high degree of intercorrelation among the counts for the trace metals. Because the PIXE analysis measures each metal independently of all other elements, these correlations represent an association of $\mathrm{Zn}, \mathrm{Fe}$, and $\mathrm{Cu}$ within individual animals. This association could represent individual differences in the ternary complexes of norepinephrine (Colburn \& Maas, 1965) such that animals with high levels of norepinephrine may also have high levels of the coordinated elements.

\section{REFERENCES}

Albert, D. J., Chew, G. L., Tobani, A., Walsh, M. L., Lee, C. Y. S., \& RYAN, J. Preoperative gentling does not attenuate septal-lesion induced hyperreactivity. Physiology \& Behavior, 1981, 27, 387-389.

Albert, D. J., W Alsh, M. L., Ryan, J., \& Siemens, Y. A comparison of the effect of preoperative gentling on the mouse killing and reactivity induced by lesions of the lateral septum, the medial accumbens nucleus, and the medial hypothalamus. Physiology \& Behavior, 1982, 28, 1117-1120.

Armario, A., Balasch, J., \& Martinez, E. Acute and chronic stress interrelationship in rat: Changes in $\mathrm{Cu}$ and $\mathrm{Zn}$ levels. Agressologie, 1981, 22, 155-158.

Bengelloun, W. A., Finklestein, J., Burright, R. G., \& Donovick, P. J. Presurgical handling and exploratory behavior of rats with septal lesions. Bulletin of the Psychonomic Society, $1977,10,503-505$.

Chafetz, M. D., Evans, S., \& Gage, F. H. Recovery of function from septal damage and the growth of sympathohippocampal fibers. Physiological Psychology, 1982, 10, 391-398.

Colburn, R. W., \& MaAs, J. W. Adenosine triphosphate-metalnorepinephrine ternary complexes and catecholamine binding. Nature, 1965, 208, 37-41.

Coscina, D. V., Goodman, J., Godse, D. D., \& Stancer, H. C. Taming effects of handling on 6-hydroxydopamine induced rage. Pharmacology, Biochemistry, and Behavior, 1975, 3, 525-528.

Dailey, J. W., \& BatTarbee, H. D. Effect of adrenalectomy on tyrosine hydroxylase activity. Neuropharmacology, 1982, 21, 287-291.

DeNelsky, G. Y., \& Denenberg, V. H. Infantile stimulation and adult exploratory behavior: Effects of handling upon tactual variation seeking. Journal of Comparative and Physiological Psychology, 1967, 63, 309-312.

Dietrich, W. D., Durham, D., Lowry, O. H., \& Woolsey, T. A. "Increased" sensory stimulation leads to changes in energy-related enzymes in the brain. Journal of Neuroscience, $1982,2,1608-1613$.
Donovick, P. J., Burright, R. G., \& Swidler, M. A. Presurgical rearing environment alters exploration, fluid consumption, and learning of septal lesioned and control rats. Physiology \& Behavior, 1973, 11, 543-553.

Doty, B. A. Effects of handling on learning of young and aged rats. Journal of Gerontology, 1968, 23, 142-144.

Evans, S. H., Chafetz, M. D., \& Gage, F. H. Taxonomic abstraction in psychobiology. Journal of General Psychology, in press.

Evans, S., Neideffer, J. D., \& Gage, F. H. APL functions for interactive data analysis: Principal components analysis. Behavior Research Methods \& Instrumentation, 1981, 13, 657-666.

Gage, F. H., Thompson, R. G., \& Valdes, J. J. Endogenous norepinephrine and serotonin within the hippocampal formation during the development and recovery from septal hyperreactivity. Pharmacology, Biochemistry, and Behavior, 1978, 9, 359-367.

Hemsworth, P. H., Barnett, J. C., \& Hamen, C. The influence of handling by humans on the behavior, growth, and corticosteroids in the juvenile female pig. Hormones and Behavior, $1981,15,396-403$.

Hennessy, J. W., \& Levine, S. Stress, arousal, and the pituitaryadrenal system: A psychoendocrine hypothesis. Progress in Psychobiology, 1979, 8, 133-178.

Hennessy, M. B., \& Levine, S. Sensitive pituitary-adrenal responsiveness to varying intensities of psychological stimulation. Physiology \& Behavior, 1978, 21, 295-297.

Kemp, K., \& Danscher, G. Multi-element analysis of the rat hippocampus by proton induced $\mathrm{x}$-ray emission spectroscopy (phosphorus, sulphur, chlorine, potassium, calcium, iron, zinc, copper, lead, bromine, and rubidium). Histochemistry, 1979, 59, 167-176.

KLECKA, W. R. Discriminant analysis (Sage University Paper Series on Quantitative Applications in the Social Sciences, Vol. 19). Beverly Hills and London: Sage Publications, 1980.

Kostarczyk, E., \& Fonberg, E. Heart rate mechanisms in instrumental conditioning reinforced by petting in dogs. Physiology \& Behavior, 1982, 28, 27-30.

Lamour, Y., Willer, J. C., \& Guilbaud, G. Rat somatosensory (SMI) cortex: I. Characteristics of neuronal responses to noxious stimulation and comparison with responses to non-noxious stimulation. Experimental Brain Research, 1983, 49, 35-45.

McEwen, B. S., \& W allach, G. Corticosterone binding to hippocampus: Nuclear and cytosol binding in vitro. Brain Research, 1973, 57, 373-386.

OGren, S. O., \& Fuxe, K. On the role of brain noradrenaline and the pituitary-adrenal axis in avoidance learning. I. Studies with corticosterone. Neuroscience Letters, 1977, 5, 291.

Olton, D. S., \& Samuelson, R. J. Remembrance of places passed: Spatial memory in rats. Journal of Experimental Psychology: Animal Behavior Processes, 1976, 2, 97-116.

Olton, D. S., Walker, J. A., \& Gage, F. H. Hippocampal connections and spatial discrimination. Brain Research, 1978, 139, 295-308.

OtTen, U., \& Thoenen, H. Modulatory role of glucocorticoids on NGF-mediated enzyme induction in organ cultures of sympathetic ganglia. Brain Research, 1976, 111, 438-441.

Pattison, S. E., \& Dunn, M. F. On the relationship of the zinc ion to the structure and function of the $7 \mathrm{~S}$ nerve growth factor protein. Biochemistry, 1975, 14, 2733-2739.

Prohaska, J. R., \& Smith, T. L. Effect of dietary or genetic copper deficiency on brain catecholamines, trace metals, and enzymes in mice and rats. Journal of Nutrition, 1982, 112, 1706-1717.

Roberts, D. C. S., \& Bloom, F. E. Adrenal steroid-induced changes in beta-adrenergic receptor binding in rat hippocampus. European Journal of Pharmacology, 1981, 74, 37-41.

SEGGIE, J. Effect of somatosensory stimulation on affective behavior of septal rats. Journal of Comparative and Physiological Psychology, 1968, 66, 820-822. 
Seggie, J., Uhlir, I., \& Brown, G. M. Adrenal stress responses following septal lesions in the rat. Neuroendocrinology, 1974, 16, 225-236.

TURNER, B. H. Neural structures involved in the rage syndrome of the rat. Journal of Comparative and Physiological Psychology, 1970, 71, 103-113.

Vinogradova, O.S. Functional organization of the limbic system in the process of registration of information: Facts and hypoth- eses. In R. L. Isaacson \& K. H. Pribram (Eds.), The hippocampus (Vol. 2). New York: Plenum, 1975.

Walsh, R. N., \& Cummins, R. A. Neural responses to therapeutic sensory environments. In R. N. Walsh \& W. T. Greenough (Eds.), Environments as therapy for brain dysfunction. New York: Plenum, 1976.

(Manuscript received July 11, 1983; revision accepted for publication October 14, 1983.) 